\title{
Artigo
}

\section{Lobo sem pele de cordeiro: o impacto do "fator Trump" para a mobilização conservadora latino-americana}

\author{
Lobo without skin of lamb: the impact of the "Trump factor" for \\ latin american conservative mobilization
}

Danillo Avellar Bragança ${ }^{1}$,

Marcello de Souza Freitas ${ }^{2}$

DOI: $10.5752 /$ P. 1809-6182.2017v14.n3.p59

\begin{abstract}
Resumo
Neste texto, os autores investigam de forma coordenada o declinio do poder norte-americano, a chegada de Donald Trump ao poder e o impacto nas políticas de integração sul-americana. Este texto demonstra como que a mudança na politica externa norte-americana ao longo desta década culminaram em câmbios institucionais importante nos paises da região e suas estruturas compartilhadas. $O$ argumento é que estes processos estão todos interligados, ainda que esparsos pelo tempo, anteriores até a Trump. Nesse sentido, demonstra-se a existência de uma janela de oportunidade, onde é possivel que, num ponto no futuro, novos arranjos podem surgir da incapacidade do mandatário norte-americano em produzir uma política consistente para a região.
\end{abstract}

Palavras-chave: Estados Unidos; integraçâo; Donald Trump; politica externa; América do Sul.

\begin{abstract}
In this paper, the authors investigate in a coordinated way the decline of American power, the arrival of Donald Trump to power and the impact on South American integration policies. This text demonstrates how the change in US foreign policy throughout this decade culminated in important institutional changes in the countries of the region and their shared structures. The argument is that these processes are all intertwined, albeit time-scattered, prior to Trump. In this sense, there is a window of opportunity, where it is possible that, at some point in the future, new arrangements may arise from the incapacity of the US agent to produce a consistent policy for the region.
\end{abstract}

Key words: U.S; integration; Donald Trump; foreign policy; South America.

\footnotetext{
1. Doutorando em Ciência Política pela Universidade Federal Fluminense e Professor-colaborador do Instituto de Estudos Estratégicos da Universidade Federal Fluminense. ORCID: 0000-0002-9503-6019

2. Doutorando no Department of International Politics na Aberystwyth University e Pesquisador do Global Communication Research Centre da Aberystwyth University. ORCID: 0000-0001-5424-5482
} 


\section{Introdução}

A imagem de Donald J. Trump está associada aos desafios que enfrentam o poder e a hegemonia norte-americanos no século XXI. O seu mote de campanha "Make America Great Again" demonstra que a manutenção do poder americano foi um tema central na última corrida presidencial estadunidense Após um controverso primeiro ano de governo, Trump continua enfrentando dificuldades em cumprir tal promessa de campanha. Este artigo fará uma breve análise sobre os impactos da política de Trump e o papel dos Estados Unidos no plano internacional para a América Latina.

Há muito tempo especialistas debatem sobre os sinais de um possível declínio do poder americano e seus impactos para a estabilidade da ordem internacional. Paul Kennedy (1988) e Immanuel Wallerstein (2004) argumentam que tal declínio poderia ser desencadeado tanto pelo excessivo exercício de seu poder de intervenção (o que traria custos crescentes para a manutençâo de sua supremacia), como pela ascensão de novos centros de poder, possibilitando o avanço de uma nova potência hegemônica, como a China (ZAKARIA, 2009). Já Joseph Nye (1990; 2004) refuta essa tese. Nye pondera que o poder americano é mais diversificado e extenso do que tais análises podem prever e, portanto, se os Estados Unidos souberem articular o seu vasto acervo de poder, que engloba tanto o hard como o soft power, o país teria condições de se sustentar como a potência hegemônica do século XXI.

O fim da Guerra Fria, desencadeado pela implosão do bloco de poder soviético, abriu caminho para um período de grande expansão do modelo liberal/capitalista (SCHOLTE, 2005) e, principalmente, para os Estados Unidos alcançarem o ápice de seu poder e exercerem uma hegemonia global sem restriçóes; o que se evidenciou durante a Guerra do Golfo com a inédita coalizão de países con- tra o Iraque liderada pelo exército norte-americano (NOGUEIRA, MESARI 2005). Contudo, no final da década de 1990, já eram notáveis os sinais de desgaste do exercício excessivo do poder de polícia global e do peso do perfil imperial dos Estados Unidos nas relaçôes internacionais (NYE, 2004).

A chegada do novo milênio foi marcada por uma crescente contestação à excessiva influência e presença de Washington em várias regiôes do mundo. A expressão mais emblemática desse sentimento antiamericano foi o atentado às Torres Gêmeas, em 11 de setembro de 2001. Osama Bin Laden justificou o ataque como resposta à ocupaçáo militar do Oriente Médio por tropas americanas e às assimetrias econômicas causadas pela difusão global do receituário neoliberal. Segundo Joseph Nye (2004), em vez de reafirmar o poder do país, a resposta do presidente Bush ao atentado, baseada na força militar unilateral e na implementação de uma agenda ultraconservadora, acabou por contribuir ainda mais para a sua deterioração, em função da onda de protestos e antiamericanismo que gerou. Nye (2004) explica que o excessivo uso do hard power, associado ao descaso com as instituiçóes multilaterais e opinião pública, comprometeu o soft power americano e a manutenção de sua hegemonia pela perda de legitimidade.

Anos mais tarde, em 2008, a crise econômica abalou mais uma vez, a imagem e a legitimidade internacional americana. Segundo especialistas, esse foi mais um sinal do progressivo declínio do poder americano (SILVEIRA, 2011; FARHI et al., 2011).

Esse processo de declínio é desacelerado com a eleição de Barack Obama, em 2009. Sua vitória gerou um otimismo global quanto à possibilidade de estar inaugurando uma fase mais benevolente do exercício do poder americano, inclusive ganhando o prêmio Nobel da Paz antes mesmo de começar seu mandato. Com isso, internamente, esperava-se recuperar parte do prestígio e do soft power que os Estados Unidos haviam perdido nos últimos anos. 
Ao término do segundo mandato de Obama, em 2017, o saldo de seu governo é razoavelmente positivo quanto a certos avanços na política doméstica, como é o caso do Obamacare e da relativa estabilização da economia após a crise. Porém, o saldo é menos positivo quando se trata de política externa. Além de ter cumprido superficialmente algumas promessas, como a retirada de parte das tropas no Iraque, Obama manteve o caráter belicoso dessa política, com o maior uso de drones, em vez de soldados (BENJAMIN, 2017).

Durante todo esse processo, um importante fator exógeno a ser considerado é o impacto da ascensão da China no poder americano. Nos últimos dez anos, o país tem surpreendido o mundo com suas altas taxas de crescimento econômico e a ampliaçáo de sua influência internacional no campo da política, economia e cultura, o que hoje o coloca nas posições de segunda economia do mundo e de potência global (MARTEL, 2012).

Mesmo mantendo um perfil mais econômico do que militar e buscando mostrar-se como um fator de estabilidade da ordem internacional e não de ruptura (o que alguns especialistas classificam como "ascensão pacífica"), a China é claramente uma desafiante da hegemonia norte-americana (ZAKARIA 2009). Ainda não está claro o real impacto que esse cenário vem gerando na manutenção do poder dos Estados Unidos e que tipo de reação o país tomará. Afinal, com o modelo sui generis de ascensão implementado pela China, formas tradicionais de balanceamento de poder poderão causar maiores rupturas na ordem internacional e, ao final, comprometer ainda mais a hegemonia americana, abrindo novos espaços de influência chinesa (MONTENEGRO, 2015).

Essas questóes expóem uma série de dilemas quanto aos rumos da política americana, na medida em que a manutenção de sua supremacia global no novo milênio dependerá de como o país vai li- dar com os principais desafios que se apresentam à sua política externa, quais sejam: o enfrentamento da crise econômica global; o combate ao terrorismo internacional (com o ISIS no topo da lista); a manutenção da estabilidade do Oriente Médio (principalmente em relação à Síria); a retomada do crescimento e da competitividade da economia norte-americana; o combate ao protecionismo europeu; o aumento da influência e da força militar da Rússia e a ascensão da China. Trump, com seu estilo controverso e imprudente de governar, parece não estar ajudando o país a encontrar os melhores caminhos para superar esses obstáculos (BANDEIRA, 2016).

Considerando esse quadro, o objetivo deste artigo é levantar a discussão sobre os possíveis impactos para a América do Sul da maneira como o governo Trump lida com os principais dilemas e desafios que se apresentam à política doméstica e externa norte-americana. Mesmo que, desde a campanha eleitoral, sua principal preocupação com o que acontece abaixo de suas fronteiras seja a questão imigratória dos mexicanos e a expansão do muro separando os Estados Unidos do México, historicamente é sabido que qualquer movimentação do governo norte-americano sempre impacta profundamente as dinâmicas internas e regionais da América Latina, mesmo quando o país não tem uma política específica para regiáo.

\section{Donald Trump chega ao poder}

A vitória de Donald J. Trump nas eleiçôes de 2016 despertou uma série de incertezas sobre os rumos dos atuais arranjos de governança global e receios quanto às possibilidades de manutenção da ordem internacional vigente. $\mathrm{O}$ pessimismo em relaçâo ao governo do "político-empresário-apresentador de televisão" norte-americano começa antes do seu mandato como presidente da nação mais 
poderosa. Ainda durante a campanha eleitoral, eram comuns - e ainda são - declarações xenófobas e propostas conservadoras de caráter nacionalista e protecionista, além de iniciativas consideradas imprudentes no campo da política internacional. É o caso de seus posicionamentos em relação à Síria, à Coreia do Norte e ao México, bem como ao Tratado de Paris.

Com a eleição de Trump, imediatamente se acirraram os conflitos de classe e social dentro dos EUA, que enfrentam graves problemas raciais e sociais e registram a pior distribuição de renda entre os países desenvolvidos, com devastador efeito para a política doméstica e suas relaçôes com o mundo desenvolvido ocidental (BARBOSA, 2014). Os direitos sociais dos cidadãos americanos sofreram dura investida, como no caso da revisão do Obamacare. Registram-se ainda ações xenófobas contra a populaçâo islâmica, como a proibição de entrada de muçulmanos no país; e imigrantes latinos, com foco principalmente na relação com o México; e muita "vista grossa" nas mobilizaçôes da extrema direita norte-americana. Lembremos ainda do atrito com a Alemanha sobre questôes econômicas e de protecionismo e as relaçóes cada vez piores com o México (BARBOSA,2014).

As bravatas de Trump, em vez de reforçarem o poder americano, têm, na verdade, diminuído o seu poder e o grau de confiabilidade e previsibilidade do sistema em encarar os EUA como um ator benéfico para a manutenção da ordem internacional. A postura do país acaba, por exemplo, por abrir espaços de penetração chinesa, criando novos pontos de contestaçáo da hegemonia norte-americana (BARBOSA,2014).

Esse complexo quadro desenha um jogo arriscado e imprevisível também para a América Latina, que, atualmente, vem sofrendo efeitos diretos da crise de 2008. Esse quadro parece se complicar em face da conturbada política externa do novo gover- no norte-americano e da atabalhoada mediação do país nas questôes de segurança da América Latina. Como foi o caso da declaração de Trump sobre possibilidade de intervenção militar como uma solução para a crise na Venezuela, que, ao invés de estabilizar, provocou mais insegurança na região. $\mathrm{O}$ mal-estar gerado exigiu que o vice-presidente estadunidense Mike Pence viajasse para Argentina, Chile e Colômbia para acalmar os ânimos.

Um governo norte-americano com um perfil tão abertamente belicoso deixou em alerta países sul-americanos (importante ressaltar a falta de atuação da diplomacia brasileira). Ainda estão vivos na memória dessas nações as intervençôes do passado e a possibilidade de esse governo abrir um horizonte conturbado nas relaçóes com a América Latina.

\section{A desarticulação do regionalismo progressista e autônomo}

Os primeiros anos do século XXI foram marcados por um novo modelo de articulação dos países sul-americanos, desencadeado pelo fracasso da aplicaçáo da cartilha neoliberal por vários governos da região. Essa mudança de paradigma impulsionou países progressistas que tinham como proposta uma economia política menos alinhada com os interesses dos EUA e mais condizentes com seus objetivos nacionais de autonomia e desenvolvimento. A integração regional e o posicionamento estratégico da América do Sul no plano internacional eram fatores de convergência entre muitas naçóes latinas naquele momento.

Esse período, conhecido como a "onda rosa", foi marcado pelas eleições de Néstor Kirchner (Argentina), Luís Inácio Lula da Silva, Evo Morales (Bolívia) e Hugo Chávez (Venezuela), entre outros, que tinham em comum a contestação ao Consenso de Washington e a rejeição ao projeto norte-a- 
mericano de integração comercial hemisférica. No lugar da antiga política alinhada aos interesses norte-americanos, surge o novo projeto de desenvolvimento nacional e a aposta em diversas iniciativas de integração que visavam diminuir a influência de Washington nos assuntos da região, ampliando sua autonomia e protagonismo global. Nessa linha, destacam-se a ampliação do Mercado Comum do Sul (MERCOSUL), a Alternativa Bolivariana para as Américas (ALBA) e a União das Nações Sul-Americanas (UNASUL).

Em 2009, quando ocorreu a primeira viagem de Obama como presidente norte-americano à Cúpula das Américas, em Trinidad e Tobago, a "onda rosa" latino-americana estava no auge. Nessa ocasião, Washington ainda tentava contornar a imagem negativa deixada pela administração Bush na opiniâo pública internacional. A soma desses fatores levava aquele governo a enfrentar um enorme ceticismo por parte dos países da regiáo, ainda que Obama buscasse demonstrar sua disposiçāo para iniciar um reset nas relaçóes hemisféricas.

De fato, a crise de 2008 parece ter sido um ponto de inflexão nas relaçóes dos EUA com a América Latina. O colapso do sistema financeiro norte-americano evidenciou a fragilidade e a instabilidade de tal sistema, pondo em xeque não só o poder americano mas também a própria sobrevivência do discurso neoliberal. Com isso, o profundo impacto da crise na economia norte-americana, bem como no plano internacional, a conturbada situação política do Oriente Médio e a competição com a ascensão chinesa levaram o governo americano a voltar seus olhos para a América Latina. Os Estados Unidos viam a regiáo como um grande mercado consumidor, uma posição geográfica estratégica para a produção de energia e lançamento de foguetes e fonte de recursos naturais cruciais, como petróleo, água, minérios e alimentos.
Em tese, esse projeto norte-americano não teria problemas em ser implantado na zona mais imediata de sua influência, que engloba México, América Central e Caribe. Muitos dos países dessa região, chamada de "lago americano" pela diplomacia estadunidense (AYERBE, 1998; BASTOS, 2012), sempre tiveram relaçôes muito próximas e submissas com o país, asseguradas ao longo da história por meio de pressōes econômicas ou pela política das canhoneiras. Além disso, se por um lado Obama pareceu resolver o impasse com Cuba ao retomar as interaçóes com o país (passo fundamental para transformar as relaçôes com países da região, que, em maior ou menor escala, tinham ligaçóes com Havana), por outro, os Estados Unidos reagiram ao projeto autônomo de Honduras apoiando a derrubada do governo de Zelaya. Essa última ação norte-americana foi contestada por organismos da América do Sul e contou com a ação da diplomacia brasileira para garantir a segurança do presidente deposto (AYERBE, 1998; BASTOS, 2012).

Mesmo diante desse cenário, a região mais intrincada para a ampliação da influência americana era a América do Sul. Vários países já estavam em estágio mais avançados de seus projetos de autonomia, desenvolvimento e integração. Além do fato de, em paralelo, formarem a Unasul, um projeto de segurança coletiva e articulação política que envolvia um grande número de países sul-americanos e que esvaziava o papel das Organizações dos Estados Americanos (OEA), instituição reconhecidamente controlada pelos EUA na regiáo.

Nesse contexto, dois grandes pontos de entrave eram o Brasil e a Venezuela. Ao longo dos governos de Lula e Dilma, o Brasil havia alcançado uma grande projeção e protagonismo externo, diversificando parceiros e estratégias de inserção internacional. Essa política externa "ativa e altiva", como se costumava dizer, não só tirava o país da órbita mais imediata de atuação dos EUA como 
também o aproximava de arranjos internacionais mais amplos que, apesar do discurso contrário, carregavam traços de articulação anti-hegemônica. Esse era o caso das iniciativas dos BRICS, do grupo IBAS, dos projetos de liderança brasileira no G20 e de um Mercosul ampliado (AMORIM, 2015). A Venezuela, por sua vez, liderava um projeto de contestação mais aberta à hegemonia norte-americana e era um foco de iniciativas de corte mais revolucionário. $\mathrm{O}$ país não se intimidava em enfrentar diretamente certos interesses internacionais ou em fazer alianças com países que figuravam na lista de inimigos de Washington, como Cuba. Esse projeto de revoluçáo bolivariana tinha como expoentes, por exemplo, a Alternativa Bolivariana e a Televisão do Sul (TeleSUR).

A desarticulação desses arranjos sul-americanos seria mais complexa e teria que ser parte de um esforço cuidadoso e bem articulado. Para tanto, foram instrumentalizados os serviços de inteligência norte-americanos, em articulação com o sistema financeiro internacional e as elites mais conservadoras de cada país da regiáo. A meta era desestabilizar governos contando com o uso das próprias instituiçóes nacionais, como o apoio das mídias corporativas desses países para a manipulação da opiniáo pública; além da instrumentalização de ONGs e movimentos políticos (financiados e orientados por think tanks liberais americanos), para a mobilização das massas populares em prol desse objetivo. Tudo isso sem a necessidade de uso das forças armadas e sem despertar a atenção pública ou gerar reações dos setores progressistas desses países.

Esse modelo "pós-moderno" de mudança de regime foi primeiro testado no golpe de Honduras de 2009 e, em seguida, aprimorado e implementado para a desestabilização do governo do Paraguai, em 2012. Uma estratégia parecida é utilizada na Argentina, onde a mídia corporativa fez uma pesada campanha de difamação dos governos Kirchner junto à opinião pública e "vendeu" Macri como um candidato de fora do cenário político tradicional e eleito pelo mercado como melhor opção. Lá, o processo envolveu a criminalização de Cristina Kirchner também, assim como no caso de Dilma Rousseff, mesmo com o notório envolvimento de Maurício Macri com offshores e esquemas de corrupção, tampouco com os muitos escândalos que envolveram Michel Temer em toda sua trajetória política. A criminalização de movimentos sociais de oposição repetiu o padrão observado no Brasil, como nos casos de Santiago Maldonado, Milagro Sala e da reforma educacional promovida por Macri, rechaçada pelos estudantes organizados do país. O abismo que se abriu na política na América do Sul ficou também evidente nas relaçóes infrarregionais, dando espaço para o afastamento da Venezuela do MERCOSUL e o esvaziamento da UNASUL.

No Brasil, o longo processo de desestabilização do governo de Dilma Rousseff, em grande medida, seguiu o receituário do "golpe brando" implementado em Honduras e no Paraguai. Como denunciado pelos vazamentos de Glenn Greenwald, o seu passo a passo contou com a espionagem de conversas pessoais de Dilma e de informaçóes estratégicas da Petrobras pelo governo americano, por meio da National Security Agency (NSA). Segundo mídias alternativas, como o "The Intercept", de Glenn Greenwald, os dados coletados por meio de grampos secretos foram entregues à Polícia Federal e ao Ministério Público brasileiros, que estavam trabalhando em colaboração com o Federal Bureau of Investigation (FBI) para iniciarem uma ampla investigação contra a corrupção com apoio da tradicional grande mídia brasileira, responsável por difundir versões enviesadas e seletivas da investigação como instrumento de propaganda e manipulação da opinião pública.

Assim, em 2016, concretiza-se o afastamento de Dilma da presidência da República por meio 
de um processo de impeachment questionável. Os vazamentos continuaram, e envolveram grandes nomes da política nacional, do presidente a deputados de muitas legendas, ministros das relaçốes exteriores, entre outros. Delações premiadas mostraram um "grande acordo nacional" envolvendo setores da mídia, o Partido do Movimento Democrático Brasileiro ( PMDB) e o Partido da Social Democracia Brasileiro (PSDB), o Judiciário e até setores dos comandos militares. Enquanto isso, reformas estruturais vão sendo promovidas, ao preço de muitas emendas constitucionais, que transformaram o Congresso Nacional em um grande balcão de negócios, comandado pelo PMDB e com endosso do Poder Judiciário. Essas reformas mexem em setores estratégicos do país, como no caso da extração de petróleo, beneficiada com refinanciamento de dívidas, renúncia fiscal e abertura para a concorrência internacional. A base de Alcântara, um tema muito debatido na década de 90, voltou a cena, dando lugar a novas especulaçôes sobre a necessidade de uma base estadunidense no país. Mudanças profundas na Constituição brasileira foram promovidas neste contexto, e envolvem, por exemplo, a venda de terras no Brasil para estrangeiros, a redução da capacidade de fiscalização da Justiça do Trabalho e o fim da publicação das listas de trabalho escravo, além das Reformas Trabalhista e da Previdência, que todas contam com o apoio explícita dos vetores políticos e do mercado que formam este quadro geral que assumiu o poder no Brasil. Esse processo envolve também uma profunda reforma educacional, além de ataques à autonomia universitária por parte do Judiciário e da Polícia Federal, como nos recentes casos na Universidade Federal de Santa Catarina (UFSC) - que levaram ao suicídio do reitor da instituição, Luiz Carlos Cancellier de Olivo - e da Universidade Federal de Minas Gerais (UFMG), sempre utilizando-se da retórica anti-progressista e de rotinas excepcionais de direito, como no caso da condução coercitiva do reitor e da vice-reitora da instituição.

Esse momento de pressão conservadora na América do Sul teve como pano de fundo a drástica queda do preço internacional do petróleo, que afetava diretamente o Brasil e a Venezuela, pagadores de grande parte dos arranjos regionais. O impacto dessa baixa do preço do petróleo fez essas economias entrarem em colapso, garantindo a melhor configuração para a implementação da mudança de regime em ambos os países e ampliando a onda de desarticulação e contra reformas neoliberais na região. É em meio a esse processo que Michel Temer chega ao poder e passa a promover uma reversão de todas as políticas progressistas, além de colocar o Brasil em alinhamento com os objetivos da política externa norte-americana e os interesses do sistema financeiro internacional, tornando o país sem voz externa autônoma e em vias de se colapsar política e economicamente.

$\mathrm{Na}$ Venezuela, a crise alcança seu nível mais crítico, com colapso econômico, carência de abastecimento, protestos violentos, atentados e ondas migratórias para fuga do país. A economia sofre sabotagem de forças externas e de burguesias nacionais, enquanto movimentos políticos de oposição ganham financiamento e orientação de think tanks americanos e suas reivindicaçóes passam a ser potencializados pelas mídias nacionais.

Qualquer reação do governo para reestabilizar a situação passa a ser rechaçada pela mídia venezuelana e uma narrativa contrária ao governo Maduro é reproduzida pela mídia global, como forma de comprometer a imagem internacional de seu governo para que sua base de sustentação seja deteriorada até a sua queda. Internacionalmente, somam-se à narrativa deturpada da crise na Venezuela a posição dúbia do MERCOSUL em relação ao país, sua inclusão na lista norte-americana de ditaduras 
inimigas e a declaração de Trump sobre possível intervençâo militar para retomada da estabilidade do país. As grandes manifestações de 2013, 2014 e 2015 contaram com amplo apoio da mídia de massa no país, e contaram com forte apoio de lideranças novas, como aquelas que vinham do Vem pra Rua e do Movimento Brasil Livre (MBL), notadamente associados à políticos de oposição. Esta relação ficou bastante evidente ao longo dos meses em que Temer assumiu interinamente, depois com a posse em definitivo e com a formação da base de apoio do governo, sempre contando com estes grupos ou para angariar apoio popular ou para divertir a atenção desta opiniáo pública para outros elementos, como no caso das censuras a museus.

Essa é uma conjuntura peculiar e que merece uma observação. Enquanto Maduro resiste e enfrenta os Estados Unidos, Temer busca uma aproximação de Trump e um alinhamento da política externa brasileira aos interesses norte-americanos, o que, por sua vez, parece improvável, visto a baixíssima qualidade da política externa brasileira sob o comando de um dos partidos da base governista, o PSDB.

\section{O efeito Trump em uma América Latina dividida}

Avaliar o impacto do que decidimos chamar de "efeito Trump na América Latina" pode parecer um exercício prematuro, em função de o presidente americano ainda estar em seu primeiro ano de mandato e, apesar da retórica e de algumas iniciativas isoladas, parecer não haver uma clara diretriz de política externa para a região - que, em muitos aspectos, é uma tradição do Partido Republicano (BANDEIRA, 2010). É justamente essa retórica que merece ser analisada aqui. Acreditamos que o perfil destemperado do presidente "valentão", que contraria qualquer formulação política mais prudente e sistemática, e suas declaraçôes insensatas de sua "diplomacia de Twitter" podem trazer efeitos imprevisíveis para os objetivos de Washington de manter a hegemonia norte-americana no mundo.

No lado das açóes mais concretas, medidas implementadas por Trump nessa fase inicial de governo podem ter algum impacto mais imediato nas dinâmicas sul-americanas. Esse é o caso do aumento das barreiras de acesso ao mercado norte-americano, para o qual muitas naçóes da região exportam a maior parte de seus produtos primários e do qual dependem para o equilíbrio de sua balança comercial. Conforme a crise do governo Maduro se agrava, Trump parece pouco interessado em criar meios diplomáticos para uma saída do impasse entre governo e opositores venezuelanos por meios democráticos e com os objetivos de estabilidade regional.

Considerando o poder americano, o quanto o país tem a perder no atual cenário global e a constante possibilidade de açóes políticas irracionais nas relaçôes internacionais, não se pode renegar totalmente as declaraçôes de Trump. Seu grau de imprevisibilidade e irracionalidade é alto e, portanto, tudo pode acontecer. Entretanto, é importante considerar que, até o momento, muito de sua retórica parece náo ter condiçóes de ter resultados, seja pela imposição de uma realidade mais intrincada e complexa da política internacional ou pela própria capacidade das instituiçóes americanas em conter as açóes de Trump, quando estas se afastam muito das diretrizes da política externa do país.

É justamente nessa agressividade pouco realizável em sua totalidade, na implementação de medidas protecionistas, no aumento da hostilidade a imigrantes latinos, no esforço em dificultar a comunicação com outros países e na aparente decisão para uma espécie de novo isolacionismo que algumas oportunidades se abrem para a rearticulação dos países da regiáo em prol de uma retomada de seus projetos de desenvolvimento e autonomia. 
Nesse aspecto, mais uma vez, os casos do Brasil e da Venezuela podem ser emblemáticos.

O caso brasileiro é marcante pelo fato de abrir grande margem para especulação sobre o quanto os serviços de inteligência norte-americanos e o seu Departamento de Estado estiveram por trás das dinâmicas sociais, ações institucionais e midiáticas que levaram ao impeachment de Dilma Rousseff. Esse processo não só levou Michel Temer ao poder, como promoveu no país um processo de implementação de medidas ultra neoliberais nos campos econômico e social e na condução da política externa brasileira.

Vale observar que, em suas declarações durante a campanha eleitoral, Hillary Clinton alertava o eleitor americano sobre a necessidade de garantir a segurança energética dos EUA em tempos difíceis para a política internacional. A observação crítica dessa declaração evidencia os interesses norte-americanos em assegurar o controle das reservas de petróleo além do Oriente Médio, e, nesse contexto, estão a Venezuela e, em segundo lugar, o pré-sal do Brasil. Trump, por sua vez, praticamente não tocou nesse assunto durante a campanha, demonstrando que, naquele momento, esse tema não estava em suas prioridades.

A eleição de Trump parece ter desarticulado momentaneamente a conjugação de forças e interesses externos e internos que levaram ao polêmico processo de impeachment no Brasil, o que, acreditamos, vem favorecendo o reagrupamento das forças progressistas brasileiras e a organização de novas investidas como resposta aos retrocessos políticos, econômicos e sociais. Com a inesperada eleição de Trump, e levando em conta ainda a sucessão de crises no governo Temer, acreditamos que os diferentes setores que formavam a cúpula do processo de impeachment hoje estáo divididos e desorientados, o que reforça nossa hipótese sobre a janela de oportunidade aberta para as forças progressistas da região.
A figura de "lobo sem pele de cordeiro" se aplica bem a Trump. Sua imprudência evidencia a face mais belicosa e intransigente do poder imperial norte-americano. Trump abre mão dos tradicionais instrumentos de manipulação cognitiva ou cooptaçấo simbólica, como a retórica de defesa de valores democráticos e a difusão da indústria cultural norte-americana e do "american way of life", a partir da "venda" mundo afora do pretenso sucesso econômico e social dos EUA, que, por tantos anos, sustentaram a hegemonia americana e difundiam globalmente a imagem de um "lobo em pele de cordeiro".

O estilo virulento de Trump conduzir os EUA ficam evidentes em sua irracionalidade, arrogância e imperícia política. O presidente norte-americano também demonstra um alto grau de imprevisibilidade, na medida em que vem encontrando dificuldade de materializar suas ideias em açôes reais. Contudo, esse pode ser o empurrão necessário para despertar consciência na América Latina. Enquanto as promessas belicosas parecem improváveis de serem cumpridas (por conta do que ainda restou de racionalidade nas instituições americanas) e as elites conservadoras da regiáo ainda se recuperam da eleição de Trump, parece que foi aberta, na dura estrutura do concerto das grandes potências, uma momentânea janela de oportunidade, que pode se configurar como um novo ponto de inflexão da história latino-americana.

\section{Conclusão}

Ainda há vários desafios para o desenvolvimento e autonomia dos países da América do Sul, como a influência dos EUA no comércio e política da região e a força reacionária das oligarquias regionais. Mas a conjunção de forças que podem levar a viradas históricas normalmente surgem em momentos de crise. Portanto, enquanto Trump continuar inflamando a crise na região por meio de suas declaraçōes e interfe- 
rência, contraditoriamente, pode acabar reforçando o espírito nacionalista e os objetivos de integração entre os países da América do Sul.

Acreditamos que erros cometidos até aqui pela política externa de Donald Trump, somados à sua aparente incapacidade de cumprir muitas de suas promessas, vem esvaziando o poder americano. Apesar de sempre haver o risco da irracionalidade tomar conta do cálculo político, levando a retórica a se transformar em açóes mais extremas, inclusive no campo militar, até então vem se materializando como demonstrações vulgares de força que, no final, se traduzem como fraqueza.nessa constatação, acreditamos que, da forma como essa retórica vem sendo direcionada para a América do Sul, cria condições para um novo despertar do orgulho regional. Ao reacender traumas da memória coletiva, cria um efeito agregador entre progressistas e setores que ainda guardam algum resquício de nacionalismo.

Nesse contexto, arranjos regionais, como o MERCOSUL e a UNASUL, podem ganhar nova força e renascer como frente de resistência. Outro caminho pode ser um maior arranjo de livre comércio para toda a América Latina. É o caso da atração do México para acordos com países sul-americanos, como uma possível associação do MERCOSUL ao Trans-Pacific Partnership (TPP), visto que os EUA se retiraram de tal iniciativa.

Portanto, a questão que fica é até que ponto a eleição de Trump gera incertezas e desestabiliza as articulações políticas dos governos ultra neoliberais que vêm tomando o poder na América do Sul. É nesse vácuo que estão caminhos para qualquer projeto que busque ampliar o desenvolvimento e a autonomia dos países sul-americanos.

\section{Referências}

AYERBE, Luis Fernando. A Política Externa Dos Estados Unidos e trajetória do desenvolvimento cubano. Perspectivas. São Paulo, 1998
AMORIM, Celso. Teerã, Ramalá e Doha - Memórias da Política Externa Ativa e Altiva. Benvirá, 2015.

BARLETT Meghan . Nobel panel saw obama peace prize as 'mistake,' new book claims,

The Washington Times, Washigton, 16 sept. 2015, disponível em: <https://www.washingtontimes.com/news/2015/sep/16/ nobel-panel-saw-obama-peace-prize-mistake-new-book/> acesso em: 19 mar. 2018

BASTOS, Pedro Paulo Zahluth. A política dos Estados Unidos: da diplomacia do dólar à boa vizinhança (1898-1933). Texto para Discussão. IE/UNICAMP, Campinas, n.204, abr. 2012 BRAGANCA, Danillo. Narcotráfico, Soberania e Relaçóes Internacionais no México. Rio de Janeiro: Gramma Editora, 2017.

CAIN Eli; SATO Erika. The Venezuela Problem: Hyper-Politicization and Fragmentation in Mercosur, Council on Hemispheric Affairs, Washington, 7 jul. 2016. Disponível em< http:// www.coha.org/the-venezuela-problem-hyper-politicization-and-fragmentation-in-mercosur/> Acesso em: 19 mar. 2018.

CRISE na Venezuela ameaça os EUA, diz Pence. Exame, São Paulo, 14 ago. 2017. Disponível em: < https://exame.abril. com.br/mundo/crise-na-venezuela-ameaca-os-eua-diz-pence/> Acesso em: 19 mar. 2017.

D'ALESSANDRO Fernando López. Os Estados unidos e sua crise, Carta Maior, São Paulo, 25 mar. 2008,Disponível em: <https://www.cartamaior.com.br/?/Editoria/ Internacional/Os-Estados-Unidos-e-sua-crise-economica-\%252525250D\%252525250A/6/14010>Acesso em: 19 mar.2018.

DANTAS Dimitrius. Reitor e Vice Reitora da UFMG são conduzidos coercivamente me operação da PF, O Globo, Rio de Janeiro, 6 dez. 2017. Disponível em: < https://oglobo.globo.com/brasil/ reitor-vice-reitora-da-ufmg-sao-conduzidos-coercitivamente-em-operacao-da-pf-22157474 > Acesso em: 19 mar. 2018.

EBOLI Evandro. Pagamentos feitos a Romero Jucá superam R \$ 22 milhóes, diz delator. Senado Federal, Brasília, 10 dez. 2016. Disponível em: <http://www2.senado.leg.br/bdsf/bitstream $/$ handle $/ \mathrm{id} / 528351 /$ noticia.html?sequence $=1>$ Acesso em : 19 mar. 2018

EUA querem 'solução pacífica' na Venezuela, diz Pence, Veja, São Paulo, 13 ago 2017. Disponível em: < https://veja.abril. com.br/mundo/eua-querem-solucao-pacifica-na-venezuela-diz-pencel > Acesso em: 19 mar. 2018.

FLECK Isabel. EUA avaliam contraproposta brasileira para uso da base de Alcântara, Folha de São Paulo, São Paulo, 29 set. 2017. Disponível em:< http://www1.folha.uol.com.br/poder/2017/09/ 1922279-eua-avaliam-contraproposta-brasileira-para-uso-da-base-de-alcantara.shtml> Acesso em: 19 mar. 2018.

FUENTES Esther ; HILDERBRAND Rachael. The Role of Pro-Impeachment Protests in Brazil's Uncertain Future, Council on Hemispheric Affairs, Washington, 15 marc. 2016. 
Disponível em: < http://www.coha.org/the-role-of-pro-impeachment-protests-in-brazils-uncertain-futurel> Acesso em: 19 mar. 2018.

GARCIA, Marco Aurélio. Dez anos de política externa, In: SADER, Emir, (ed.) Dez anos de governos pós-neoliberais no Brasil: Lula e Dilma. Rio de Janeiro: FLACSO Brasil, 2013.

MANRIQUEZ, Jose Luis; NAVEJAS, Francisco Javier. Atrapado sin salida? Mexico ante los gigantes asiáticos - China e Índia. In: OLIVEIRA, Henrique Altemani de (coord.). China e Índia na América Latina: Oportunidades e desafios. Curitiba: Juruá, 2010.

MARTEL, Frédéric. Mainstream - a Guerra Global Das Mídias e Das Culturas. Civilização Brasileira, 2012

MATIENZO, Eugenia. Milagro Sala, otro capítulo de violación a los DDHH en Argentina, Council on Hemispheric Affairs, Washington, 22 set. 2018. Disponível em: < http:// www.coha.org/milagro-sala-otro-capitulo-de-violacion-a-los-ddhh-en-argentina/> Acesso em: 19 mar. 2018.

McCARTHY Tom. Can Trump really make America great again? The Guardian, Pennsylvania, 18 jan 2017. Disponível em: < https://www.theguardian.com/us-news/2017/jan/17/ donald-trump-america-great-again-northampton-county-pennsylvania> Acesso em: 19 mar 2018.

MITCHELL Robie. The Pink Tide Recedes: End of An Era? , Council on Hemispheric Affairs, Washington, 14 jul. 2016. Disponível em: < http://www.coha.org/the-pink-tide-recedes-end-of-an-era/> Acesso em: 19 mar. 2018.

MONIZ BANDEIRA, Luiz Alberto. Brasil, Argentina e Estados Unidos - Conflito e Integração na América do Sul Tríplice Aliança. Civilização Brasileira, 2010

MONIZ BANDEIRA, Luiz Alberto. A Desordem Mundial. Civilização Brasileira, 2016

MONTENEGRO, Renan Holanda. Crise ou afirmaçáo da hegemonia americana? Arrighi, Wallerstein, Fiori e Zakaria, 2016

NYE, Joseph. Bound to Lead: The Changing Nature of American Power. Basic Books, 1990.

NYE, Joseph. Soft Power: The Means to Success in World Politics. PublicAffairs, 2004.

NOGUEIRA, João Pontes \& MESSARI,囚 Nizar. Teorias de Relaçóes Internacionais. Correntes e Debates. Elsevier, 2005

PAIVA Aline. Post-Coup Brazil: Temer's Rise to Power and the New State of Exception, Council on Hemispheric Affairs, Washington, 22 jun. 2017. Disponível em: < http://www. coha.org/post-coup-brazil-temers-rise-to-power-and-the-new-state-of-exception/> Acesso em: 19 mar. 2018.

PEDROZA, Luicy. Gasoline into Fire. GIGA Focus Latin America, n.1, 2017.

RESENDE Narley. Suicídio: reitor da UFSC que havia sido preso é encontrado morto, Paraná Portal, Curitiba, 2 out. 2017. Disponível em: < http://paranaportal.uol.com.br/cida- des/dias-apos-sair-da-prisao-reitor-da-ufsc-comete-suicidio/> Acesso em: 19 mar. 2018.

SARAIVA, Miriam G. Estancamento e crise da liderança brasileira no entorno regional. In: SERBIN, Andrei (Ed.). ¿¿Fin de ciclo y reconfiguración regional? América Latina y las relaciones entre Cuba y los EUA. Buenos Aires: CRIES, 2016.

SILVEIRA, Stefano José Caetano da. Crise Da Hegemonia Americana E Da Globalizaçáo: Mudança Ou Continuidade? Século XXI. Porto Alegre, V. 2, No1, jan-jul 2011.

SCHOLTE, Jan Aart. Globalization: A Critical Introduction. Palgrave, 2005

SCHREIBER, Mariana. "Cinco Visōes: Como Os Protestos Vão Impactar O Processo De Impeachment”? BBC Brasil, Brasília, 14 mar. 2016. Disponível em: < http://www.bbc. com/portuguese/noticias/2016/03/160311_protestos_analise_ms.>Acesso em: 19 mar. 2018

WALLERSTEIN, Immanuel. The Decline of American Power: The U.S. in a Chaotic World. The New Press, 2000.

WOLFFE Richard. How Trump's foreign policy threatens to make America weak again, The Guardian, London, 2 jul. 2017. Disponível em: < https://www.theguardian.com/us-news/2017/jul/02/donald-trump-foreign-policy-diplomacy> Acesso em: 19 mar. 2018.

TOLEDO Marcelo. Criticada por ambientalistas, venda de terras para estrangeiros volta à tona, Folha de Sáo Paulo, São Paulo, 17 set. 2017. Disponível em: < http://www1.folha.uol. com.br/mercado/2017/09/1918963-criticada-por-ambientalistas-venda-de-terras-para-estrangeiros-volta-a-tona.shtml> Acesso em :19 mar. 2018

TRUMP afirma que os Estados Unidos não descartam uma opção militar na Venezuela. BBC Brasil, São Paulo,11 ago 2017. Disponível em: < http://www.bbc.com/portuguese/internacional-40907714 >Acesso em: 19 mar. 2018.

ZAKARIA, Fareed.The Post-American World: And The Rise Of The Rest. Penguin, 2009

ZIBECHI, Raul. Brasil Potência: Entre a integração regional e um novo imperialismo. Rio de Janeiro: Consequência, 2012. 